DOI: $10.17805 /$ zpu.2019.1.15

\title{
Подходы к оценке ценности социальных проектов
}

\author{
Н. В. ФЕДОРОВА, О. Ю. МИНЧЕНКОВА \\ МОСКОВСКИЙ ГУМАНИТАРНЫЙ УНИВЕРСИТЕТ
}

В статье рассмотрены подходы к определению понятия «ценность социального проекта», предложена его авторская трактовка, увязывающая важность, значимость, полезность проекта в той или иной социальной сфере с традиционными критериями - время, масштаб, стоимость и качество.

Выявлено, что создание ценности социального проекта возможно благодаря воспроизведению уникальных свойств проекта в рамках достижения миссии социально-экономической системы. Особое внимание уделено ценности, которая проявляется в процессе реализации социального проекта. Разграничены ценность в процессе создания проекта и ценность продукта проекта; в этом контексте рассмотрены все стороны социального проекта - от заказчика до потребителя.

Указаны характерные проявления ценности социального проекта, формирующиеся в двух направлениях: в процессе создания продукта проекта и во время управления проектом. Выделены общие характеристики ценности проекта. Проведен анализ соответствия каждой составляющей ценности проекта ожиданиям заинтересованных сторон. Проведена классификация видов ценности проекта в соответствии с фазами реализации проекта. Осуществлен анализ условий и факторов создания ценности проекта для основных заинтересованных сторон.

Ключевые слова: ценность; социальный проект; стейкхолдер; заказчик; управление проектом 


\section{ВВЕАЕНИЕ}

$\mathbf{Q}$ настоящее время все больше ученых уделяют пристальное внимание изучению В проблемы ценности социального проекта как наиболее сложной форме социального действия. Социальный проект - это сконструированное инициатором проекта социальное нововведение, целью которого является создание, модернизация или поддержание в изменившейся среде материальной или духовной ценности, которое имеет пространственно-временные и ресурсные границы и воздействие которого на людей признается положительным по своему социальному значению (Ауков, 2007: 36).

Социальный проект предполагает создание нового, ранее не существовавшего социально значимого продукта. В Российской Федерации реализуется значительное количество социальных проектов в таких сферах жизни, как культура, искусство, религия, экология, спорт и здоровый образ жизни, образование и наука, поддержка одаренных детей и молодежи, поддержка социально незащищенных слоев населения, социальный маркетинг. Проекты реализуются также в сфере благотворительности, ЖКХ, СМИ, в корпорациях и организациях, при развитии межнационального сотрудничества и т. А. Поэтому на повестке дня стоит вопрос об оценке ценности социального проекта.

\section{ПОНЯТИЯ И ВИАЫ ЦЕННОСТИ ПРОЕКТА}

Стоит различать понятие стоимости и ценности социального проекта. Ценность социального проекта - это его важность, значимость, польза, полезность в той или иной социальной сфере, а стоимость - это выраженная в денежном эквиваленте величина затрат на его разработку и обслуживание.

Ценность социального проекта может оцениваться по критерию его успешности, который в сочетании с классическими критериями - время, объем, стоимость и качество - может отразить все ожидания заинтересованных лиц проекта (стейкхолдеров). На сегодня продолжается дискуссия среди специалистов-практиков и ученых по трактовке понятия «ценность» в управлении социальными проектами.

Основы применения ценности основаны на отличном от традиционного восприятия социальных проектов как средств достижения намеченной цели. Если ранее проект считался временным действием, то в современных условиях деятельность организации становится постоянно проектно-ориентированной и свидетельствует о ее эффективности.

В разные периоды проблематикой определения ценности проекта занимались такие отечественные и иностранные ученые, как Р. А. Арчибальд, Ч. Кроуфорд, Аж. Пеннипекер, М. А. Разу, В. И. Воропаев, В. А. Шапиро, И. И. Мазур и др.

Сегодня основной задачей всех организаций является распределение ресурсов таким образом, чтобы максимизировать ценность портфеля проектов в соответствии с главной миссией (например, долгосрочная рентабельность, окупаемость по инвестициям (ROI от англ. return on investment), повышение возможного успеха проекта).

Аля успеха организации важно выявлять и управлять ценностью на всех фазах жизненного цикла социального проекта, а не только на этапе эксплуатации продукта проекта, так как в этот период реализации проекта ценность проявляется через призму показателей ROI, рентабельности и других и носит только финансово-экономический характер. 
Ч. Кроуфорд и Аж. Пеннипекер убеждены, что вычисления ROI в управлении проектами нельзя считать достаточным для оценки их ценности. Авторы отмечают, что истинная ценность управления проектами существует «в нематериальной сфере», и выступают за использование подхода, основанного на сбалансированной системе оценок. Ч. Кроуфорд и Аж. Пеннипекер опираются на результаты опроса 100 руководителей проектов высшего звена, проведенного компанией Center for Business Practices - исследовательским отделением компании PM Solutions (Crawford, Pennypacker, 2001: 4). Такой подход к толкованию ценности проектов является более аргументированным и имеет социально-экономическую подоплеку.

Впрочем, несмотря авторитетность мнений и достаточное количество исследований, остается открытым вопрос об обеспечении ценности для всех заинтересованных сторон проекта.

Создание ценности социального проекта возможно благодаря воспроизведению уникальных свойств проекта в рамках достижения миссии социально-экономической системы. Однако это мнение не в полной мере отражает сущностное наполнение и создание ценности на всех стадиях выполнения проекта - от замысла проекта до получения результата продукта проекта и его эксплуатации. Стоит обратить внимание на ценность, которая проявляется в процессе реализации социального проекта. Таким образом, желательно разграничивать ценность в процессе создания проекта и ценность продукта проекта; и в таком контексте необходимо охватить всех стейкходдеров социального проекта - от заказчика до потребителя.

Можно определить ценность как выгоду, полученную от реализации интересов всех заинтересованных сторон, как комплексный показатель, состоящий из ценности процесса, продукта и ценности организации, которая работает над проектом. Однако круг стейкходдеров, которые заинтересованы в ценности проекта, в данном подходе описан недостаточно.

Обращает на себя внимание позиция некоторых авторов, которые считают, что для проектов устанавливается специальная миссия, которая может быть определена как «предоставление конкретной ценности конкретным заинтересованным сторонам». В Руководстве по управлению инновационными проектами и программами организаций (P2M «A Guidebook of Project and Program Management for Enterprise Innovation») (Стандарты управления проектами: Электронный ресурс), указаны такие характерные проявления ценности:

- ценность активов организации;

— интеллектуальная ценность и ценность инноваций;

- ценность владельца;

- ценность как компромисс интересов заинтересованных сторон;

- ценность как синергия для будущего выгодного сотрудничества или новой модели кросс-индустриального бизнеса;

- новая социальная ценность для общества;

- ценность бизнес-интересов (инновации, прибыльность, компании, рост, стабильность и надежность организации).

Позиции ученых и практиков являются взвешенными относительно определения ценности проекта, однако ценность требует определенных уточнений и доработок. Ценность социального проекта - это выгоды от продукта проекта и процесса управления проектом, которые ожидаются и обеспечиваются во время его реализации с учетом интересов всех стейкхолдеров. 
ХАРАКТЕРИСТИКА СОСТАВАЯЮЩИХ ЦЕННОСТИ

Ценность должна объединять множество составляющих (рис. 1).

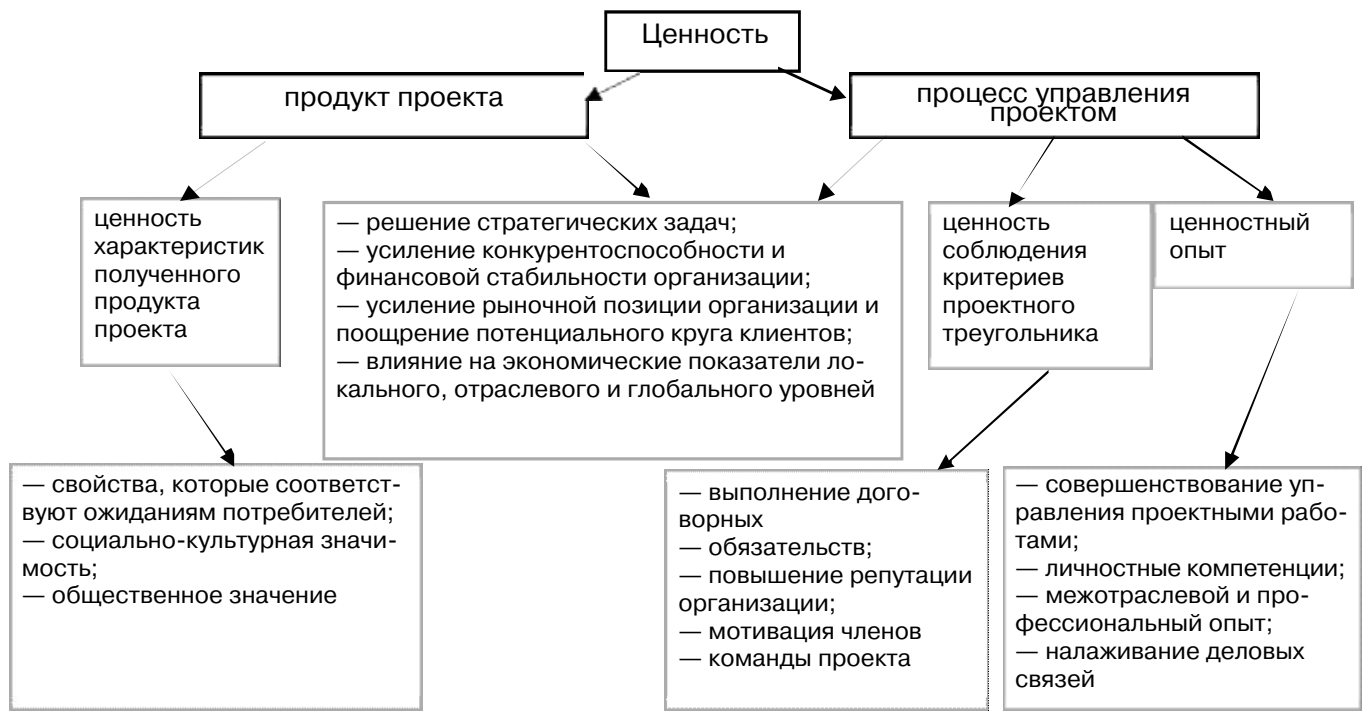

Рис. 1. Основные составляющие иенности проекта

Fig. 1. The main components of a project value

Все составляющие ценности социального проекта проявляются в двух направлениях: в процессе создания продукта проекта и во время управления проектом. Таким образом, сформулируем видение ключевых составляющих ценности проекта, которые будут отвечать этим двум аспектам и будут иметь общие характеристики.

1. Соответствие полученных свойств продукта проекта запланированным и ожидаемым характеристикам, что в достаточной мере удовлетворяет потребности всех стейкхолдеров.

2. Соответствие продукта проекта стратегическим целям и задачам организации, повышающим уровень ее конкурентоспособности.

3. Соответствие проекта установленным критериям проектного треугольника, т. е. соблюдение времени проекта, бюджета и качества.

4. Приобретение и аккумулирование опыта участников проекта, формирование обновленной базы знаний, способствующей совершенствованию методологии и инструментария проектного управления.

В этом контексте внимание заслуживает то, что анализ литературы, которая содержит трактовки понятия «заинтересованные стороны проекта», показал наличие большого количества подходов и разных взглядов на их разделение относительно видов и групп (Donaldson, Preston, 1995: 81; Freeman, 1984: 138; Bendheim, 1998: 324; Holzer, 2008: 53). В исследовании мы будем опираться на разделение стейкхолдеров по стандартам Р2М. Заинтересованными лицами проекта можно считать тех, кто непосредственно участвует в процессе его реализации (заказчик, куратор, менеджер проекта, функциональный руководитель проекта, члены проектной команды, подрядчики, поставщики, инвесторы) и в дальнейшем получает ценность от продукта проекта во время его использования (потребитель, общество, правительство). 
Итак, в классическом понимании такой подход расширяет круг представителей заинтересованных сторон социального проекта и побуждает к рациональному созданию ценности и управления ею.

\section{ЦЕННОСТНЫЕ ОЖИААНИЯ СТЕЙХОААЕРОВ ОТ ПРОЕКТА}

Опираясь на представленные выше характерные составляющие ценности социального проекта и на интересы стейкходдеров, каждый из которых имеет собственные ожидания, необходимо провести всесторонний анализ соответствия каждой его составляющей ожиданиям заинтересованных сторон (табл.).

ЦЕННОСТНЫЕ ОЖИААНИЯ СТЕЙКХОААЕРОВ ПРОЕКТА VALUE EXPECTATIONS OF THE STAKEHOLDERS OF A PROJECT

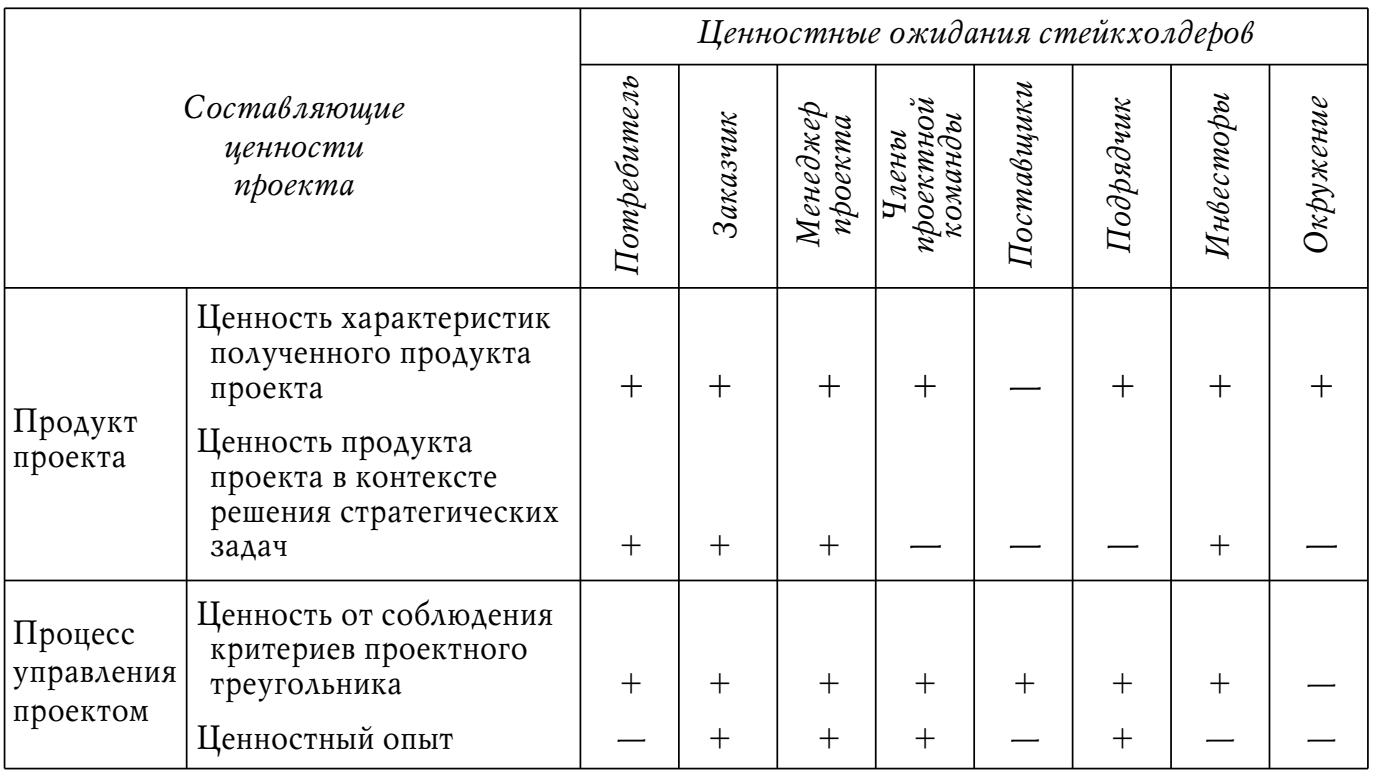

В основе видения ценности лежит следующая позиция, которая характеризуется следующими аспектами:

- для масштабной группы стейкхолдеров-потребителей ценность обеспечивается соответствием характеристик продукта социального проекта их потребностям и ожиданиям, определяя их уровень удовлетворенности;

- для заказчика, руководителя проекта, проектной команды и инвестора проекта ценность имеет проявление во всех составляющих;

- Аля поставщиков и подрядчиков ценность проявляется в создании продукта проекта с соблюдением всех классических критериев оценки проекта и в приобретении опыта с целью долгосрочного сотрудничества;

- Аля окружения ценностным является получение желаемого результата от создания и использования продукта социального проекта, в том числе с учетом социальных и экологических факторов.

\section{ОЦЕНКА УСПЕШНОСТИ СОЦИААЬНОГО ПРОЕКТА}

Учитывая все вышеуказанное, предлагается определенная трансформация представления классических критериев оценки успешности социального проекта (рис. 2). 


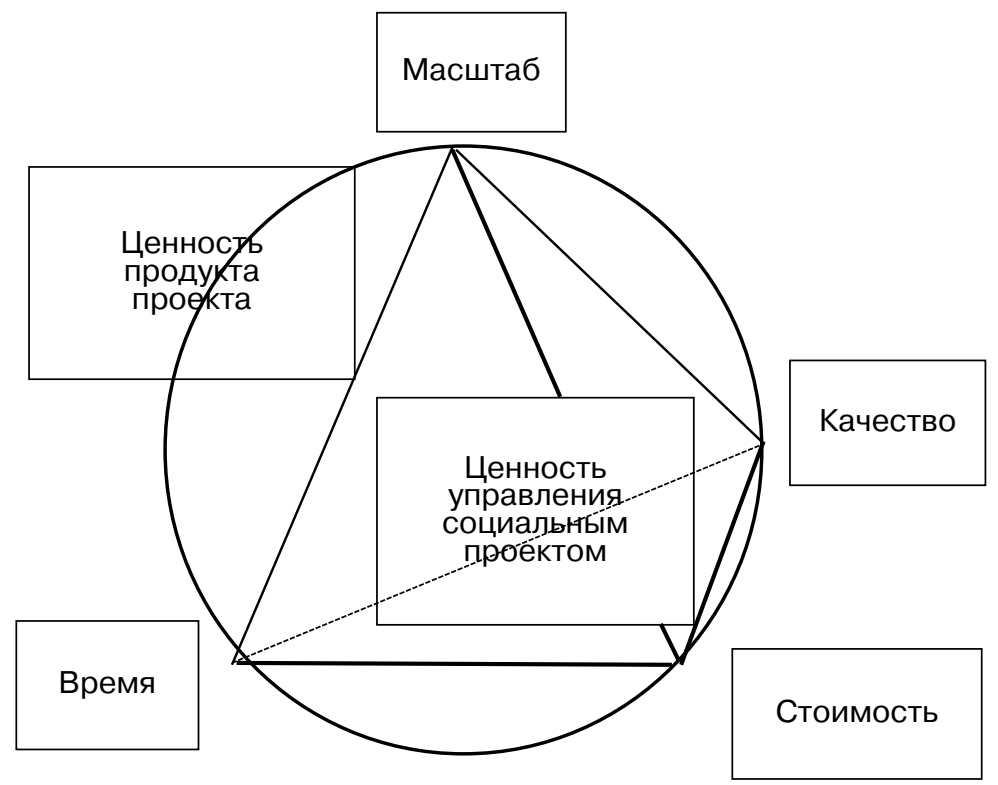

Pис. 2. Современные критерии оченки успешности проекта

Fig. 2. Modern assessment criteria of project success

Аанная позиция (рис. 2) заключается в том, что ценность социального проекта формируется и создается в процессе его управления, которое затрагивает ряд параметров (время, масштаб, стоимость, качество), и использования продукта проекта, а также проявляется в отдаленных последствиях во время эксплуатации его результатов.

Также стоит заметить, что анализ дитературных источников свидетельствует о различных взглядах на выделение видов ценности проекта. Некоторые авторы выделяют такие признаки ценности, как аспект жизнедеятельности (социальная, духовная, материальная ценность), характер восприятия категории (субъективная, объективная ценность), этапы реализации (потенциальная ценность, реализованная ценность), форма создания (частная, публичная ценность), ценность для стейкхолдеров (ценность для собственника бизнеса, Аля инвестора, для внутренних субъектов организации и для других стейкхолдеров). Но описанные подходы имеют недостатки, поэтому можно дополнить существующие наработки и ввести градацию видов ценности проекта (рис. 3, см. с. 198).

Классификация видов ценности создается с учетом всех фаз реализации проекта - от начала (замысел) к результатам использования полученного продукта проекта, вместе с тем эти ценности могут подвергаться определенным преобразованиям и должны подпадать под непрерывный контроль на протяжении всего жизненного цикла проекта.

Эта позиция заключается в следующем:

1) ценность инициации проекта заключается в утверждении его целесообразности и необходимости, описывает все вероятные ожидания стейкхолдеров и может предсказать конкурентные преимущества от внедрения продукта проекта;

2) ценность планирования и реализации проявляется в учете всех очевидных и скрытых затрат проекта, определении его временных, бюджетных, качественных ха- 
Виды ценности проекта

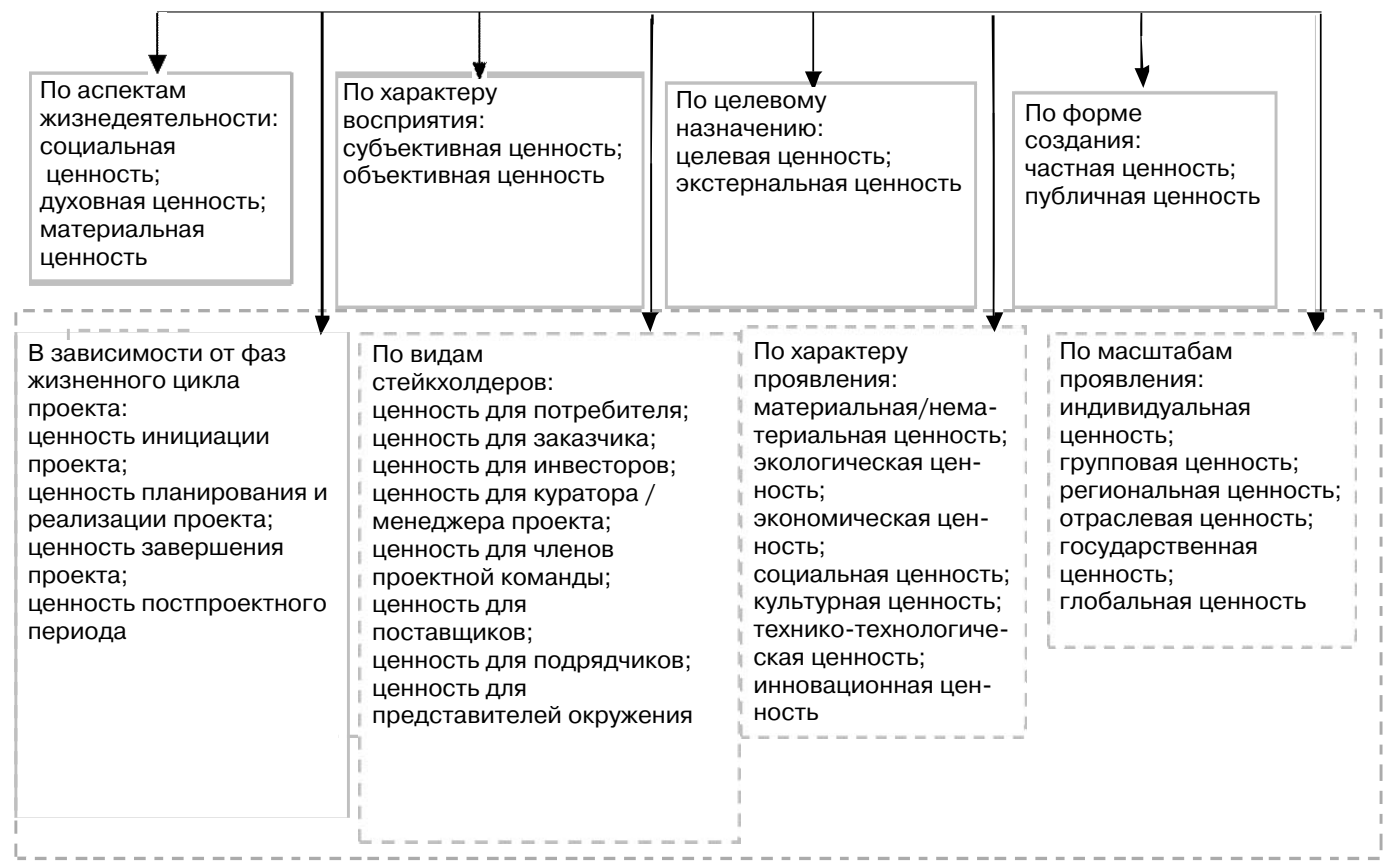

Рис. 3. Виды иенности проекта

Fig. 3. Types of project value

рактеристик свойств продукта социального проекта и создает основания для получения желаемых результатов и предсказания возможных последствий проекта с получением запланированного продукта проекта надлежащего качества, количества, в рамках бюджета и времени его выполнения;

3) ценность завершения проекта аккумулирует опыт управления проектом;

4) ценность постпроектного периода представляет собой генерацию создания ценности через продукт и последствия проекта для обеспечения соответствующих ожиданий потребителей, заказчика, инвестора и окружения.

\section{ЗАКАЮЧЕНИЕ}

В процессе управления проектом разработанные выше характеристики ценности являются отражением индивидуальных ожиданий различных заинтересованных сторон проекта. Так, для заказчика и инвестора важным будет проявление ценности в финансовых выгодах от реализации проекта. Аля менеджера проекта и членов проектной команды ценность будет заключаться в приобретении опыта, накоплении знаний, в частности в междисциплинарных отраслях, а также в возможности карьерного роста, умении налаживать и поддерживать взаимоотношения. Аля поставщика ценность будет иметь проявление в получении заказов и поддержании деловых взаимосвязей в текущем периоде и с перспективой будущего сотрудничества. Аля потребителей и окружения ценностными будут продукт проекта и результаты реализованного проекта, которые позволят удовлетворять потребности всех заинтересованных сторон. 
Соответственно проявление ценности в продукте проекта может касаться лица (заказчика), группы людей (членов проектной команды) или общества в целом (широкого круга заинтересованных лиц), что в дальнейшем будет иметь определенные последствия деятельности организаций, формирующих изменения в отраслях экономики на государственном уровне и в межгосударственных взаимоотношениях (в глобальном пространстве).

Изменения в теории проектного управления соответствуют требованиям практики его применения и обусловливают расширение критериев оценки успешности проектов. Ценность проекта выступает таким критерием, который, наряду с существующими, характеризует успех проекта. Именно поэтому требуют уточнения и пересмотра подходы к устоявшимся принципам управления проектами, а также анализ существующих наработок по управлению ценностью проектов.

\section{СПИСОК АИТЕРАТУРЫ}

Ауков, В. А. (2007) Социальное проектирование. М. : Изд-во Моск. гуманит. ун-та ; Флинта. 240 c.

Стандарты управления проектами [Электронный ресурс] // Проектная практика. URL: https://pmpractice.ru/knowledgebase/normative/projectstandarts/ (дата обращения: 15.12.2018).

Bendheim, C. L. (1998) Determining Best Practices in Corporate- Stakeholder Relations using Data Envelopment Analysis: An Industry Level Etudy // Business and Society. № 37 (3). P. 306-338.

Crawford, J. K., Pennypacker, J. S. (2001) The value of Project Management: Proof at last // Proceedings of the PMI 2001 Seminar and Symposium. Nashville, TN, Newtown Square, PA : Project Management Institute, November 1-10.

Donaldson, T., Preston, L. E. (1995) The stakeholder theory of the corporation: Concepts, evidence and implications // Academy of Management Review. № 20. P. 65-91.

Freeman, E. (1984) Strategic Management: a Stakeholder Approach // Journal of Management Studies. № 29(2). P. 131-154.

Newbould, G., Luffman, G. (1989), Successful Business Politics. London : Gower. 78 p.

Holzer, B. (2008) Turning Stakeseekers into Stakeholders // Business and Society. № 47 (1). P. 50-55.

Ohara, S. (2001) «A Guidebook for Project and Program Management for Enterprise Innovatoin» (P2M). Issued by the Project Management Professionals Certification Center (PMCC) of Japan (Project Management Association of Japan (PMAJ). Japan. 90 p.

Аата поступления: 17.12.2018 2.

\section{APPROACHES TO THE VALUE ASSESSMENT OF SOCIAL PROJECTS \\ N. V. FEDOROVA, O. YU. MINCHENKOVA MOSCOW UNIVERSITY FOR THE HUMANITIES}

The article considers approaches to the definition of the concept of the «value of a social project»; it offers its author's interpretation, pointing out the importance, significance, and usefulness of the project in a particular social sphere with traditional criteria - time, scale, cost and quality.

It is revealed that it is possible to create the value of a social project thanks to the reproduction of the unique characteristics of the project within achievement of the mission of the social and economic system. Particular attention is focused on the value that manifests itself in the implementation of the social project. The authors distinguish between the value in the process of creating a project and the value of the project product; in this context, all the stakeholders of the social project are considered - from the customer to the consumer.

The characteristic manifestations of the value of a social project are indicated; those are formed in two directions: in the process of creating the project product and during the project management. The 
article highlights the general characteristics of the project value. The authors analyze the correlation of each component of the project value with the expectations of the stakeholders and classify the types of project value in compliance with the phases of the project implementation. They analyze the conditions and factors of the creation of project value for the main stakeholders.

Keywords: value; social project; stakeholder; customer; project management

\section{REFERENCES}

Lukov, V. A. (2007) Sotsial'noe proektirovanie. Moscow, Izd-vo Mosk. gumanit. un-ta, Flinta. 240 s. (In Russ.).

Standarty upravleniia proektami. Proektnaia praktika [online] Available at: https://pmpractice.ru/knowledgebase/normative/ projectstandarts/ (access date: 15.12.2018). (In Russ.).

Bendheim, C. L. (1998) Determining Best Practices in Corporate- Stakeholder Relations using Data Envelopment Analysis: An Industry Level Etudy. Business and Society, no. 37 (3), pp. 306-338.

Crawford, J. K. and Pennypacker, J. S. (2001) The value of Project Management: Proof at last. In: Proceedings of the PMI 2001 Seminar and Symposium. Nashville, TN, Newtown Square, PA, Project Management Institute, November 1-10.

Donaldson, T. and Preston, L. E. (1995) The stakeholder theory of the corporation: Concepts, evidence and implications. Academy of Management Review, no. 20, pp. 65-91.

Freeman, E. (1984) Strategic Management: a Stakeholder Approach. Journal of Management Studies, no. 29(2), pp. 131-154.

Newbould, G. and Luffman, G. (1989) Successful Business Politics. London : Gower. 78 p.

Holzer, B. (2008) Turning Stakeseekers into Stakeholders. Business and Society, no. 47 (1), pp. 50-55.

Ohara, S. (2001) «A Guidebook for Project and Program Management for Enterprise Innovatoin» (P2M). Issued by the Project Management Professionals Certification Center (PMCC) of Japan (Project Management Association of Japan (PMAJ). Japan. 90 p.

Submission date: 17.12.2018.

Федорова Наталья Васильевна - кандидат экономических наук, доцент, профессор кафедры менеджмента Московского гуманитарного университета. Адрес: 111395 г. Москва, ул. Юности, 5, корп. 3, ауд.612. Тел.: +7 (499) 374-70-13. Эл. адрес: kafedra612@mail.ru

Минченкова Ольга Юрьевна - доктор экономических наук, профессор; профессор кафедры менеджмента Московского гуманитарного университета. Адрес: 111395, Россия, г. Москва, ул. Юности, д. 5, корп. 2. Тел.: +7 (499) 374-70-13. Эл. адрес: kafedra612@mail.ru

Fedorova Natalya Vasilyevna, Candidate of Economics, Associate Professor, Professor, Department of Management, Moscow University for the Humanities. Postal address: 5, Yunosti St., Moscow, Russian Federation, 111395. Tel.: +7 (499) 374-70-13. E-mail: kafedra612@mail.ru

Minchenkova Olga Yuryevna, Doctor of Economic sciences, professor, professor of the Department of management, Moscow University for the Humanities. Postal address: 5, Yunosti St., Moscow, Russian Federation, 111395. Tel.: +7 (499) 374-70-13. E-mail: kafedra612@mail.ru 